\title{
The Adaptive Significance of Cultural Behavior
}

\author{
William H. Durham ${ }^{1}$
}

In this article, I argue that human social behavior is a product of the coevolution of human biology and culture. While critical of attempts by anthropologists to explain cultural practices as if they were independent of the ability of individual human beings to survive and reproduce, I am also leery of attempts by biologists to explain the consistencies between neo-Darwinian theory and cultural behavior as the result of natural selection for that behavior. Instead, I propose that both biological and cultural attributes of human beings result to a large degree from the selective retention of traits that enhance the inclusive fitnesses of individuals in their environments. Aspects of human biology and culture may be adaptive in the same sense despite differences between the mechanisms of selection and regardiess of their relative importance in the evolution of a trait. The old idea that organic and cultural evolution are complementary can thus be used to provide new explanations for why people do what they do.

KEY WORDS: biological and cultural evolution; adaptiveness; fitness; cultural behavior.

\section{INTRODUCTION}

For many years, biologists and anthropologists have realized that the organic and the cultural evolution of human beings have been interdependent, mutually complementary processes (e.g., Roe and Simpson, 1958; Caspari, 1963; Dobzhansky, 1961, 1962, 1963; Montagu, 1962, 1968a,b; McBride, 1971). In anthropology, this realization prompted the analysis of cultures and social systems as superorganic extensions of human adaptation (e.g., Cohen, 1974b; Meggers, 1971, 1973; Rappaport, 1969, 1971a,b; Sanders and Price, 1968;

This article was prepared from remarks I presented at the Smithsonian Conference on Human Biogeography in April 1974. Help with phenotypic costs came from an NSF Predoctoral Fellowship and the University of Michigan Society of Fellows.

${ }^{1}$ Department of Zoology and Society of Fellows. University of Michigan, Ann Arbor, Michigan. 
Steward, 1955; Vayda, 1969). The major contention has been that cultural practices provide people with the behavioral means of adjustment to the physical and social conditions of their lives (Harris, 1974; Rappaport, 1969, 1971 a,b;Vayda, 1961). However, ecological anthropology has suffered from a lack of agreement about how best to characterize adaptation and about how to describe the processes producing it ( $c f$. Alland and McCay, 1973; Flannery, 1972).

In biology, the interdependence of human organic and cultural evolution has sometimes been taken to mean that cultural practices may be interpreted from a knowledge of natural selection and genetic change (Simpson, 1964, 1966, 1972; Emlen, 1966; Freedman, 1967, 1968; Alexander, 1971, 1974). The interest of biologists in cultural behavior has increased recently with studies showing how even complex social interactions can in theory evolve by differential reproduction (Hamilton, 1963, 1964, 1970, 1971, 1972; Trivers, 1971, 1972, 1974; Wilson, 1971, 1975; Alexander, 1974). Unfortunately, biological theories of ad. aptation do not yet make adequate allowance for learning and nongenetic inheritance. The implication of "sociobiology" has sometimes been that common forms of human social behavior are the direct result of natural selection and gene expression. It has been easy to forget that even a close correlation between biological theory and observed behavior in no way constitutes evidence of causation. The apparent consistencies between biological theory and cultural behavior may also result from a complementary process of cultural evolution.

The rather chauvinistic adherence to traditional disciplinary biases has had a major role in preventing anthropologists and biologists from attaining a more thorough understanding of human cultural behavior. To date, there remains a tendency to debate biology vs. culture or instinct vs. learning, and this tendency has almost totally obscured the suggested complementarity of organic and cultural evolution. For example, many anthropologists continue to insist that "culture patterns are not genetically derived and, therefore cannot be analyzed in the same way as organic features" (Steward, 1955: 32; see also Kaplan and Manners, 1972). Accordingly, theories of culture change either have ignored organic evolution completely or have emphasized how the two are separate and distinct processes. Few have seriously considered that complementary evolution means that many of our biological and cultural attributes can be analyzed in the same terms even if they result from fundamentally different processes.

Biologists are also responsible for the failure to use complementarity as a conceptual tool for understanding human behavior. It is certainly not complementary to assume that all adaptive human traits are the product of gene frequency changes wrought by natural selection. Yet this is the implicit assumption of any attempt to use conventional evolutionary biology for explaining social customs. Even the few recent "interdisciplinary" studies sometimes resort to the explanation of human behavior as the direct product of gene expression and natural selection (e.g., Tiger and Fox, 1966, 1971). One finds statements like 
"The taboo on slaughter and beef eating [in India] may be as much a product of natural selection as the small bodies and fantastic recuperative powers of the zebu breeds" (Harris, 1974: 21). While I agree that many customs do have the "survival value" these authors describe (this is, in fact, a part of complementarity as explained below), I find no reason to believe that cultural practices therefore arise by natural selection. By convention, natural selection refers to the differential reproduction of individuals within a population because of genetic differences among them (Alcock, 1975). It remains to date a genetic theory and is thus neither adequate nor appropriate for explaining behaviors that can readily evolve prior to changes in the gene pool (cf. Alland, 1972, 1973).

In short, the anthropologists' reluctance to consider basic principles of evolutionary biology and the biologists' failure to provide for cultural transmission in the evolution of adaptive traits have prevented the formulation of a general theory of human evolution where natural selection and culture change really are complementary. Anthropologists are no doubt correct in insisting that cultural processes are fundamental to understanding human social behavior. Biologists are no doubt correct in insisting that "man's [sic] cultural history and his reproductive history are by no means independent of one another" (as reemphasized by Alexander, 1974: 368). In a truly complementary theory, both would be right. In order to achieve a more complete understanding of human social behavior, it is therefore reasonable to seek a general theory of cultural change which is explicitly compatible with the theory of organic evolution by natural selection.

In my opinion, the key to a complementary theory of cultural evolution lies in the observation of numerous scholars (both anthropologists and biologists) that culture is generally adaptive in the biological sense (e.g., Dobzhansky, 1961: 286; Mettler, 1962: 183ff; Simpson, 1964: 99; Alland, 1972: 21, 1973: 233; Meggers, 1971: 4). This suggests, first, that culture is an important part of the means by which human beings sustain themselves in a given environment. There is nothing particularly novel or controversial in this statement (cf. Rappaport, 1971b). More importantly, however, the observation also suggests that a theory of culture change must be able to explain how, by cultural means, people evolve social behaviors that contribute to their ability to survive and reproduce in their habitat. This creates a serious problem: for reasons explained below, not one of the existing theories of culture can explain just how cultural behaviors come to be adaptive in this biological sense. To be sure, these theories have provided a great deal of insight into the workings of human social systems. However, a theory of cultural evolution modified so as to generate truly complementary adaptations may have important new implications for our understanding of culture. My purpose here is to suggest a possible complementary theory and to evaluate critically its problems and possibilities for contributing to our understanding of human ecology and behavior. 


\section{TOWARD A COMPLEMENTARY THEORY OF CULTURAL EVOLUTION}

Most recent theories of cultural evolution assume a mechanism of selective retention (Murdock, 1956; Campbell, 1965; Ruyle, 1973; Corning, 1974; Cloak, 1975). Practices observed in the ethnographic present are believed to be the cumulative products of the selective propagation of ancestral variants. Conceptually, this view requires that there be sources of variation, consistent selection criteria, and effective mechanisms for the retention of positively selected variants. As Campbell (1965) has emphasized, a "cultural selection" theory with these features is broadly analogous to the theory of organic evolution by natural selection. The analogy, however, is not sufficient by itself to produce complementary cultural adaptations. For better understanding of the additional requirements, it is appropriate to review several recent developments in neo-Darwinian theory that have greatly influenced our understanding of biological adaptation.

\section{Adaptation by Natural Selection}

According to the theory of evolution by natural selection, each genetic characteristic of an organism is the result of generations of differential gene propagation. Genes for traits that give their bearers an advantage in terms of survival and reproduction relative to conspecifics inevitably increase their representation in the population gene pool at the expense of less prolific variants. In time, this process results in the selective retention of traits that enhance the ability of their bearers to survive and reproduce in a given environment.

In principle, the differential propagation of genes can occur through the differential reproduction of organisms at several different levels, including the differential reproduction (natural selection) of individuals, relatives, social groups, demes, species, communities, and even ecosystems ( $c f$. Lewontin, 1970; Wilson, 1973b). It must be emphasized that selection can occur on all of these levels and that concurrent selection on different levels may have opposing or reinforcing effects on gene propagation (Darlington, 1972). However, in recent years biologists have come to recognize the individual reproductive organism as the principal, though not exclusive, unit of natural selection. There are two reasons for this. First, under most conceivable conditions the differential reproduction of individuals within populations occurs at a higher rate and therefore has a more pronounced effect on evolution than the differential extinction and replacement of whole groups of individuals (see Williams, 1966, 1971). Second, even when selection above the individual level does affect gene frequencies in a population, intergroup diversity must first have arisen through the differential reproduction of individuals (Darlington, 1972). This means that only under unusual natural conditions can higher-level selection occur with enough regularity to counteract interindividual selection. Consequently, organic evolution gen- 
erally results in the selective retention of genetic traits that enhance the ability of individual organisms to survive and reproduce in a given environment. Selection for socially beneficial self-sacrifice is probably rare, although perhaps important in special cases.

This remarkably simple argument has major implications for evolutionary biology including several that have been appreciated only in the last year or two. It says, for example, that nearly every one of those characteristics traditionally called adaptations by biologists has probably evolved because of a positive contribution to the individual organism's ability to survive and reproduce in its habitat. In the past, biologists too often resorted to some form of group selection to explain complicated adaptations, particularly those behaviors thought to be genetically controlled. For example, this kind of explanation was given for many of the complex interactions in nonhuman animal societies (e.g., WynneEdwards, 1962, 1963). It has recently been argued that most if not all of these social behaviors can in fact result from interindividual selection (reviewed in Alexander, 1974). Although many of these ideas still await empirical verification, most biologists would now agree that natural selection operates most commonly at the level of individuals and, therefore, generally results in the retention of traits which enhance individual survival and reproduction.

Ultimately, of course, natural selection reduces to genetic competition. It follows that the best measure of an organism's ability to survive and reproduce in a given environment is its "relative fitness," defined as the long-term representation of an individual's genes in a given population. Because of its usefulness in explaining the evolution of genetic traits, fitness plays a prominent role in modern biology. Unfortunately, the concept has elsewhere fallen into ill repute, particularly in the social sciences, largely as the result of reification and misuse. I must emphasize that there is nothing inherently evil in fitness when it is used properly - as a measure of the relative ability of conspecifics to survive and reproduce. In summary, the point to be made here is that a complementary theory of cultural evolution will have to contend with the discovery that the adaptive significance of most genetically programmed traits lies in their contribution to the individual organism's fitness. To be adaptive in the general biological sense, cultural practices must tend to enhance the fitness of individual human beings.

A second important addition to neo-Darwinian theory began with the realization that the fitnesses of individual organisms are not independent. To begin with, biologists now recognize the overlapping reproductive interests of genetic relatives. Hamilton (1964) introduced the concept of "inclusive fitness" to account for the contributions from the reproduction of relatives to the representation of an individual's genes, and now most evolutionary theories in biology consider the reproductive success of an individual to include a kinship component in addition to fecundity and survivorship (see West Eberhard, 1975). Moreover, it is now recognized that the evolutionary competition of genes does not necessarily prevent or preclude cooperation, even between nonrelatives, as is 
sometimes implied (e.g., Hardin, 1959). There are several ways by which cooperative social interactions can result in mutually enhanced genetic representation (see, e.g., Trivers, 1971; Alexander, 1974). Thus while the individual remains central to the course of organic evolution, natural selection does not treat individuals as independents. Somehow a complementary theory of cultural evolution must not only recognize the reproductive interests of individuals but must also make allowance for the overlapping interests of relatives, mates, cooperators, reciprocators, etc.

\section{Adaptation by Cultural Selection}

With these recent developments in mind, we can return to complementarity and the three elements of cultural selection: (1) sources of variation, (2) selection criteria, and (3) mechanisms for the retention of positively selected variants. In the history of culture theory, the first of these has posed no particular problem and indeed it poses no problem for complementarity. Invention, diffusion, and accident are all known to be sources of variability in cultural traits (Barnett, 1953; Johnson, 1972), and they surely provide sufficient raw material for an evolutionary process.

But consider element (3): any theory of selective retention requires one or more mechanisms for the differential propagation of traits. In organic evolution, this is normally achieved through the "natural" differential reproduction of individuals (as we have seen). Because the transmission of cultural attributes is obviously not restricted to the act of fertilization, most theories of cultural evolution involve some process of differential replication. In some way, cultural attributes are differentially adopted and spread (see, e.g., Cavalli-Sforza and Feldman, 1973). However, many of these theories automatically assume that differential replication at the group level or even system level is of overriding importance (e.g., Carneiro, 1970b; Harris, 1971). The confusion in the biological literature, reviewed in Stern (1970), is no doubt partly responsible. The implication in many cases is that cultural evolution normally results in the selective retention of traits which actually sacrifice the ability of individual human beings to survive and reproduce in the interest of other individuals or the group (for examples, see Stott, 1962; Meggers, 1971). If indeed cultural evolution normally complements the course of natural selection, this is very unlikely. Cultural behaviors would seldom be biologically adaptive if group-level cultural selection commonly resulted in reproductive altruism.

Unfortunately, with our present knowledge it is not obvious what the various mechanisms of cultural retention are, how they function, or how they relate to one another. Surely some practices are retained as a result of each individual's personal experiences and some as the result of socialization and teaching based on the previous experience of others. In many societies, certain customs are re- 
tained and controlled by specialists such as shamans and priests who accumulate a body of privileged knowledge and carefully restrict its transmission. To be sure, traits may also spread by the conquest and replacement of groups. But as with organic evolution the important point is not the possibility but the effectiveness and direction of selection at different levels. Again for complementarity, evolutionary biology would suggest the possibility that interindividual selective retention has had the major role in shaping cultural practices. This point was recently argued by Ruyle (1973), who contends that, in theory, the spread of a practice which is learned can occur much more readily by individual adoption than by intersocietal selection. While this seems reasonable, there are to my knowledge no empirical studies explicitly comparing the effects of retention at alternative levels.

Element (2) of selective retention presents even more serious difficulties. Within anthropology itself, disagreement over the criteria of selection has proved to be a major problem in developing a satisfactory theory of cultural evolution. According to one interpretation, for example, people in a society tend to retain innovations which increase their harvest of energy from a habitat or their efficiency of energy use. Cultural change then results from "the improvement of the mechanical means with which energy is harnessed and put to work as well as by increasing the amounts of energy employed" (White, 1949: 375). From this perspective, "Adaptation in man [sic] is the process by which he makes effective use for productive ends of the energy potential in his habitat" (Cohen, 1974a: 46). Energy has thus been used by these authors and others not only to describe the specific adaptation of social groups to particular environments but also to characterize general or unilinear stages of cultural evolution (see also Cook, 1971). Although this view has been criticized in a number of ways, there is little doubt that energy utilization does increase with some kinds of cultural change. However, it does not well explain sociai behaviors remotely related to energy (e.g., incest avoidance, infanticide, headhunting), nor does it offer a good reason why energy utilization should be the relevant criterion of selection in the first place. If the importance of energy is ultimately for "carrying on the life process" or for "the struggle for existence and survival" as White suggested $(1949,1959)$, should we not consider measures related to these as the criteria behind the retention of energy-harvesting practices and others? Similar criticisms can be made for the various other criteria that have been proposed including arguments that people selectively retain practices that increase the size of their social group, raise the culture-specific carrying capacity of their habitat, maintain homeostatic or regulatory relations with their environment, or provide satisfaction for their members (as summarized in Durham, 1975). None of these has proved sufficient to stand for the general case, and it remains a possibility that these measures are the correlates of at least one other, perhaps more general, criterion.

I believe it is reasonable to suggest that the inclusive fitness of individual human beings has been an important general criterion behind the evolution of 
cultural traits by selective retention (Durham, 1974). This suggestion is attractive for several reasons. First, it would account for the complementary, interdependent courses of organic and cultural evolution. Second, it could explain the consistencies between biological theory and cultural behavior without explicitly or implicitly presuming the genetic programming of everything we do. Third, it would at last enable biologists and cultural anthropologists to mean the same thing by "adaptation." Fourth, it constitutes a hypothesis for the evolution of cultural adaptations that can be tested by both fieldwork and library research. Moreover, it could mean that inclusive fitness may serve both anthropologists and biologists as a useful, analytical tool for understanding human cultural behavior. In the following section, I summarize briefly what this proposition entails.

\section{Cultural Selection and Fitness}

My proposal actually contains two major hypotheses: (1) that cultural evolution results in large part from the interindividual selective retention of cultural at tributes and (2) that the inclusive fitness of individuals (again including survivorship, fecundity, and contributions from the reproduction of relatives) has been an important general criterion guiding this selective retention.

The first hypothesis is not altogether new or unusual (cf. Ruyle, 1973). It simply suggests that what we observe now as a group phenomenon may have been molded over time by the interests and actions of individuals. This in no way denies that culture is a group characteristic. Rather, it says that the specific cultural features of a group may have evolved primarily as the result of the coordinated activities of individuals who were faced with many of the same problems and found better solutions for themselves by working together than by trying alone. It says that the key to understanding cultural behaviors may lie not in what these behaviors contribute to the welfare of the group and survival of the culture per se but rather in their consequences for the lives of individuals (see also Goldschmidt, 1972; Barkow, 1973). If indeed this is the case, then we would expect cultural practices maintained from generation to generation to result in some advantage to individual members of social groups. If, for some reason, traditional customs come to demand net reproductive sacrifice, we would expect either rapid change or rapid disintegration in the social fabric. This, of course, is exactly what we find (e.g., Turnbull, 1972). Moreover, if individuals do play an important role in cultural evolution then there is a possibility that certain individuals may somehow gain a more-than-equal share of influence in shaping cultural practices. As discussed below, this also appears to be the case. It is therefore my belief that the usual analytic focus on system-supporting functions and group survival in ecological anthropology has tended to obscure the highly influential behavior of individuals within these systems and groups (Durham, 
1974). In order to accept or reject hypothesis (1), we will need to look more closely at the role of individuals in culture change and at the relationship of change at this level to higher levels.

Hypothesis (2) of my proposition is both more unusual and easier to criticize. It suggests, for example, that humans tend to behave in ways which maximize the propagation of their genes in a given environment. From my experience, people initially find this difficult to accept and for several good reasons. First, the relevance of genetic criteria such as inclusive fitness to the study of cultural behavior, which is in large part learned, is not at all clear a priori. Immediately this brings to mind the futile, academic polemics of instinct and learning. One the other hand, there is increasing evidence that learned behavior in nonhuman animals potentially contributes to the genetic fitnesses of individuals (Kummer, 1971). There is also the evidence (reviewed in Montagu, 1962, 1968a, b) suggesting that a "positive feedback relation existed between cultural and genetic change" during the course of human evolution (Caspari, 1963: 168). It bears reemphasis that, regardless of the relative importance of these categories of change, it would not be possible to speak of positive feedback between them if they tended to produce phenotypic change in different, antagonistic directions. The common suggestion by biologists and anthropologists alike that "culture is an adaptive mechanism supplemental to, but not incompatible with biological adaptation" (Dobzhansky, 1961: 286) then means that individual inclusive fitness is surely relevant to understanding cultural behavior.

It is also commonly argued that the human "capacity for culture" is itself a product of natural selection and genetic change (e.g., Dobzhansky and Montagu, 1947; Spuhler, 1959; Waddington, 1960; Caspari, 1963; Dobzhansky, 1972). It is reasonable to assume that during the evolution of this capacity natural selection would have suppressed any organic predisposition for culturally acquiring phenotypic traits that reduce biological adaptation. At the same time, positive feedback at this level somehow might have genetically canalized our learning processes to favor the retention of learned characteristics which enhance inclusive fitness. Several authors have suggested the possibility of internal "structural rules" which guide the selective retention of cultural attributes according to "internal selection criteria" of the human brain itself (see, e.g., Corning, 1974; Alland, 1975). Certainly there is a genetic basis to pleasurable sensory reinforcements that accompany certain kinds of actions. This is not to deny that to an important extent we also learn how to learn.

Perhaps a more important reason for suggesting the relevance of fitness to understanding human activities is implied by a statement from Harner (1973: 152): "Culture is learned and transmitted through human effort; therefore it seems unlikely that cultural institutions and traits can be successfully passed on through centuries and millennia without having some regular reinforcement for their maintenance." Who would deny that successful rearing of offspring and 
dedicated participation in kinship systems are, generally speaking, fundamental and regular reinforcements of various kinds?

It is also difficult to accept a fitness argument because it hinges upon what biologists call "genotypic selfishness" (after Alexander, 1974) and emphasizes the importance of individuals and self-interest in cultural change. Often this is taken to mean that all individuals are pitted one against every other in a relentless competition for gene propogation. This could not be farther from the truth; humans do not live like the independent atoms of an ideal gas as demographers and modelers so often assume. We tend to associate into at least two important kinds of coalitions where we as individuals derive more benefit from cooperation than from competition: (1) Coalitions of genetic relatives. As discussed earlier, genotypic selfishness does not prescribe a struggle of all against all, but suggests that relatives may go a long way toward helping each other by virtue of their overlapping genetic composition. (2) Coalitions for mutual benefit. Ironically, the most self-serving behavior is often cooperation and collective participation. Maximizing fitness does not necessitate the competitive "struggle for existence" that biologists have often emphasized, for there can be great advantages even to nonrelatives who cooperate in resource harvest or defense, or who reciprocate altruistic favors (see Trivers, 1971; Alexander, 1974). It is unfortunate that biologists (including the author) so often choose words which heavily emphasize competition.

It is also commonly asked why, if inclusive, fitness really is so important to human behavior, people are not universally aware of such a fundamental standard. While it is true that inclusive fitness has almost never been used in the academic literature on cultural behavior, I believe that people do show a remarkable amount of conscious concern for the welfare of their children and relatives, and do readily recognize the parameters of their own well-being. For the scientific analysis of complex behaviors, it may be necessary to have an esoteric, academic understanding of the fitness concept, but for the purposes of leading a happy and fulfilling life one can get by on an awareness that includes no formalized cost/benefit analysis or confidence limits. There are a few studies which suggest that people are extremely sensitive to factors that influence their ability to give birth to and raise healthy children (Whiting, 1964; Katz et al., 1974). All the theory outlined here would require is a sense of self-interest consistent with the notion of inclusive fitness or a sensitivity to the welfare of one's children and relatives. For many behaviors it can be argued that any greater awareness of inclusive fitness may have been disadvantageous in the course of cultural evolution (cf. Alexander, 1975b).

When these factors are taken into account, the hypothesis that humans tend to behave in ways that maximize the propagation of their genes may not seem so farfetched. The possibility that cultural change occurs most readily at the level of individuals and often bears relation to inclusive fitness is at least worthy of consideration both in theory and empirical research. Unless we can 
categorically reject these hypotheses, we now run the risk both of ignoring a potentially useful analytical tool and of overemphasizing intersocietal selection, which may well be a much less potent force behind cultural evolution.

\section{PROBLEMS IN THEORY AND APPLICATION}

There are a number of more serious criticisms that apply to any attempt at using inclusive fitness to understand human social behavior. First, any test of the important hypotheses is complicated by characteristic features of human life history. For example, the relatively long life span of our species allows for the coexistence of a bewildering variety of distinct and potentially successful temporal strategies for genetic representation. Identifying and interpreting strategies even in one small society may be an overwhelming task. Long life span also means that individuals in groups may interact with one another for years - conditions favoring the operation of reciprocal altruism. Acts that appear counter to "genotypic selfishness" in the short term can be misleading since they may have subtle long-term compensations. Thus adequate tests of the hypotheses may require years of observation and data. With such longevity, it is also possible for the physical and/or social properties of the environment to change enough during an individual's lifetime to render a traditionally advantageous strategy maladaptive. In some cases, the costs of deleting a particular cultural trait from the social system may exceed its recent detrimental effects, thereby resulting in a form of cultural inertia. When the environmental changes are not immediately obvious, inertial behaviors may be difficult to interpret. Furthermore, long mean life expectancies make it difficult to obtain indicators of fitness, especially in the span of the average research grant. Accurate historical genealogies may be necessary for even a first approximation.

Second, there are problems of measurement associated with the notion of fitness itself. Surprisingly enough, it is not at all obvious what and when one should count to get a reliable indication of an individual's long-term genetic success ( $c f$. Lewontin, 1974: 235ff). For the analysis of some traits, the number of offspring raised to maturity by carriers of the trait may be adequate (Kummer, 1971). The adaptive significance of others may require numbers of nephews, nieces, grandchildren, great-grandchildren, or even great-grandchildren and great-nephews and -nieces. Generally speaking, fitness differentials may be satisfactorily approximated by differences in the "reproductive success" $\left(S_{i j}\right)$ of parents, where $S_{i j}$ is the number of descendants of an individual $i$ alive $j$ generations later (in most situations, the higher the value of $j$ the better the approximation). Contributions from the reproduction of relatives can be added to $S_{i j}$ using average "offspring equivalents" for a more inclusive measure (e.g., West Eberhard, 1975: 6). However, the point remains that there does not exist a single, simple measure which is by itself necessary and sufficient to describe fitness dif- 
ferentials. Nor is there a well-defined convention or agreement about what constitutes a sufficient time interval for this comparison.

To make matters worse, environmental heterogeneity means that fitness does not depend on its components (fecundity, survivorship, and kinship) in the same way in all places. A low fecundity/high survivorship combination, for example, may result in maximum fitness in one environment while the exact opposite "strategy" may be optimal under different conditions. Even for organisms whose strategies are genetically programmed, there remain theoretical problems to specifying the optimal combinations for different environmental conditions (see, e.g., Wilbur et al., 1974). A complete understanding of the adaptive significance of larger or smaller families or of extended vs. nuclear family organization in the case of humans may prove even more difficult. There are real problems for an evolutionary interpretation of cultural behavior.

Still another problem in assessing the adaptive significance of a practice by this criterion arises from the addition or transfer of functions. It may be impossible to judge from the contemporary ecological setting of a group what the original fitness-enhancing benefits were in times past. New and confounding functions may be acquired by old behaviors, or an activity which evolved for one reason may now have a completely different function. Alexander (1975b) has encountered this problem in the analysis of incest taboos discussed below. We may never understand the origins of certain customs. However, the sooner we begin to collect data suitable for directly testing these hypotheses the less tenuous our inferences need be.

\section{Determinism}

Two even more serious criticisms can be made of an evolutionary approach to human behavior. The first of these concerns the biological determinism that creeps into studies that enthusiastically try to analyze the evolution of all phenotypic characters within the context of natural selection. While the approach suggested here does indeed view human social behavior as a product of evolutionary processes, it suggests that we must be critical of any attempt to explain even "genotypically selfish" human behavior as the result of changes in genotype and hence a direct product of natural selection alone. There are good reasons for believing that the cultural selection of traits, which occurs whenever individuals selectively retain one variant over another, consciously or not, may account for the origin and maintenance of more forms of cultural behavior than do mutation and changes in the frequency of the presumed behavior genes. Firsi, the variability upon which cultural selection operates is not restricted to information introduced by random, rare events. There is evidence, for example, that even very uniform- and traditional-looking practices may harbor substantial variability, some of which, unlike genetic variability, is a response to perceived need (John- 
son, 1972). Furthermore, the hypothesized process of cultural selection can operate much more quickly than can natural selection and is not necessarily subject to the same degree of reshuffling and recombination that characterizes the transmission of genetic material. By providing a means of adaptation which is both more constant in stable environments and more flexible in changing environments, culture can thus greatly enhance the ability of social behavior to "track" environmental conditions. Moreover, cultural responses to environmental changes can affect the selection pressure for a genetic response. It is perhaps ironic that as we evolved the capacity for culture we evolved a way to reduce or even eliminate many (though evidently not all, $c f$. Bajema, 1971) of the organic selection pressures that would have favored the very refinements of genetic control required by theories that explain everything as the result of natural selection. On the basis of these arguments, I suggest that until we have other compelling evidence that a given human behavior has a genetic basis, the demonstration that such behavior has adaptive functions does not by any means prove it to be the product of natural selection. The same sort of parsimony that evolutionary biologists have used to refute group selection arguments (Williams, 1966) duly applies to their own uncritical use of natural selection to interpret human cultural behavior.

\section{Reductionism}

An evolutionary interpretation of human affairs can leave itself open to another major criticism: reductionism. A tenet of evolutionary biology is that the theory of evolution by natural selection can explain everything an organism is and does. Studies attempting to apply this theory in rigorous form to humans often imply that everything we do can be reduced to principles of human biology. In my opinion, these studies make at least two mistakes.

Mistake No. 1 comes from the presumption that, unless we deny natural selection, cultural traits can always be traced to genetic bases even if there is considerable nonbiological modifying influence. This reasoning does not deny a cultural input to social behavior, but neither does it admit that natural selection may be inappropriate for explaining many customs. Rather, it simply assumes that there are underlying genes for each particular kind of human activity. Speaking of cooperation, for example, one author put it this way: "Cultural evolution seems to be basically biological. Given human genes, a wide diversity of habitats, and sufficient time, the genes seem to interact and recombine in a way that produces people who are not only able to cooperate, but actually able to do so on a large scale" (Bigelow, 1969: 94). There are now several such interpretations that reduce human history and cultural behavior to basic biology, "biogrammar," or genetic structure and composition (see, e.g., Tiger and Fox, 1971; Darlington, 1969). 
The theory outlined above suggests that the process of cultural evolution can be separated from biological evolution even if the two are complementary. An important consequence of this is that existing cultural practices themselves form a part of the environmental influences or pressures that affect the ongoing evolution of culture. It is then theoretically possible for some cultural innovations to be advantageous and therefore selectively retained because of other local cultural features and not because of inherent biological properties. This would imply that the explanation of cultural traits cannot be reduced simply to genetic predispositions or biogrammars as the ardent natural selectionists believe.

Mistake No. 2 arises from the biological premise that adaptive significance is the total significance of any trait in any organism. Alexander (1975b), for example, argues repeatedly that "Unless Darwin was wrong, we have evolved to maximize the reproduction of our own genetic materials, and to do nothing else." Statements like this imply that theories built solely upon differential reproduction will someday explain all of human behavior and social organization. It is one thing to say that the inclusive fitness of individual human beings can be used as $a$ tool to aid our understanding of human behavior. It is quite another thing to suggest that it is the tool or even the best tool for all human behaviors.

In this case, the problem arises from the assumption of evolutionary biology, probably realistic for most animals studied by biologists, that there is a biologically limited amount of time and energy available to each organism. It is believed that natural selection adjusts the genetic influences on behavior so that this time and energy (which I will call "phenotypic costs") are spent in ways that tend to maximize the representation of a given individual's genes. Of course, different behaviors differentially reduce (or risk reduction of) the remaining "budget" and hence will affect an individual's future ability to survive, reproduce, raise offspring, aid relatives and reciprocators, etc., to differing degrees. In theory, natural selection will favor only those behaviors whose resulting fitness benefits exceed the fitness costs incurred by reductions in the balance totals of time and energy. On the further assumptions (1) that the behaviors of an individual organism can be distinguished and separated for the purposes of analysis and (2) that indicators of fitness cost and benefit can be assigned to each one in a particular environment, we would then expect the fitness benefits of evolved behaviors to exceed the fitness costs with a general pattern as in Fig. 1A. The convex nature of this relationship is expected from the component selection pressures to reduce fitness costs for all behaviors with a given benefit and to increase the benefits associated with a given cost as shown for the hypothetical behavior "P."

Human behavior presents a problem for this kind of analysis. To an extent that is certainly unique among living forms, people have the ability to use nongenetic means to extend the effective time and energy budgets for their lives beyond individual biological limits. Through the inheritance of resources or opportunities, for example, or through the accumulation of wealth, people can 
A

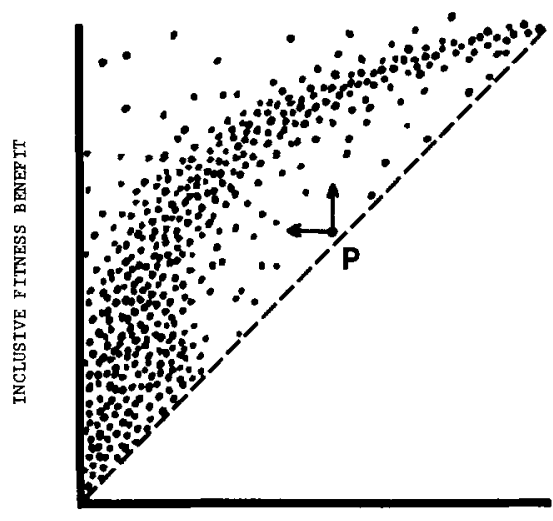

INCLUSIVE FITNESS COST
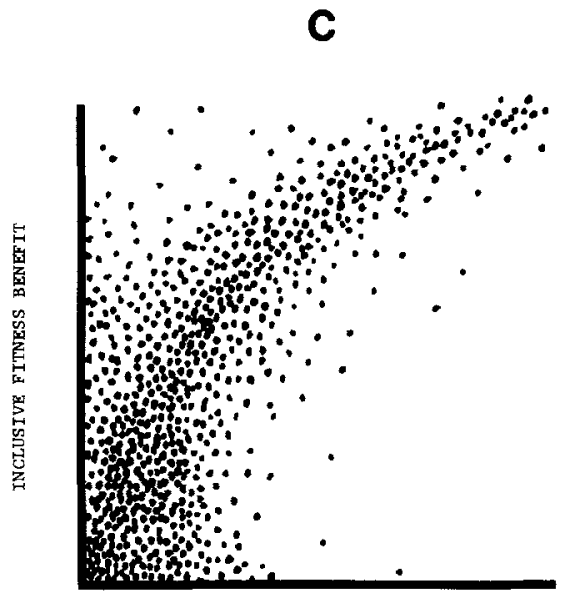

PHENOTYPIC COST
B

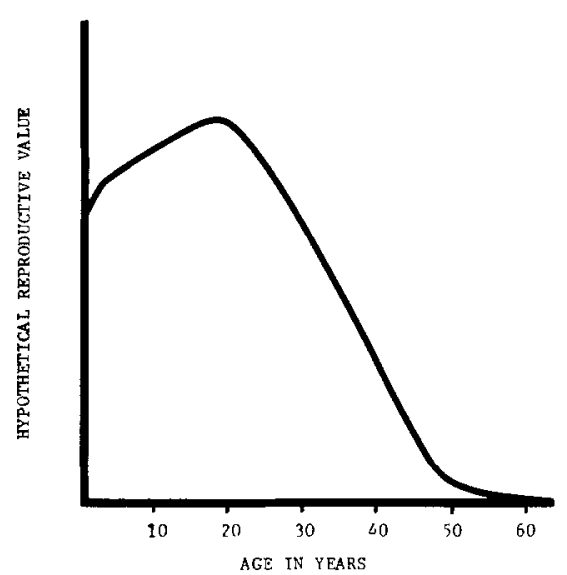

D

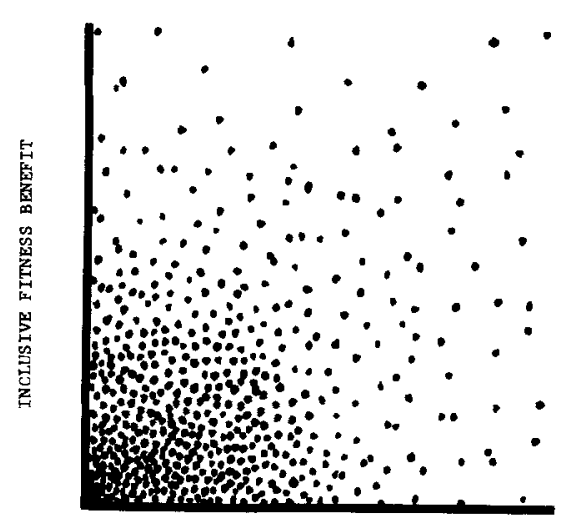

PHENOTYPTC COST

Fig. 1. (A) Hypothetical scatter diagram expected on the basis of natural selection for the inclusive fitness costs and benefits of genetically programmed behaviors by an individual organism. The convex nature of the relationship is expected from the component selection pressures as shown for behavior "P." If cultural evolution normally complements organic evolution, a similar pattern is expected for human behaviors. For the empirical analysis of human behaviors, however, inclusive fitness costs may be difficult to determine. (B) Expenditures of time and/or energy ("phenotypic costs") can be used as estimates of inclusive fitness costs, particularly if weighted by the average "reproductive value" for an individual of a given age. A purely hypothetical reproductive value is shown here as a function of age. (C) The hypothesized relationship between phenotypic cost estimates and inclusive fitness benefits for human cultural behaviors. Considerable unexplained variance is expected because the adaptive significance of human behaviors is not likely to be their total significance. (D) The comparable scatter diagram expected by the null hypothesis which claims that cultural practices are independent of our ability to survive and reproduce. 
expand the time and energy available for their uses to such an extent that sizable expenditures can be made primarily for their phenotypic returns, without significantly affecting reproductive success. Unlike organisms with genetically fixed maxima, culture can provide human beings with the luxury of phenotypic expenditures that are both phenotypically delightful and also much less consequential in terms of relative inclusive fitness. Among other things, this then enables wellendowed individuals to make behavioral expenditures with such high phenotypic costs and low genotypic benefits as would constitute an evolutionary "mistake" for someone on a smaller budget. It is likely that the selective retention of these behaviors is contingent more upon phenotypic criteria (aesthetics, pleasure, etc.) than genotypic. The point is simple: to the extent that one is culturally affluent one can afford to indulge in phenotypic rewards without committing any relative reproductive sacrifice. Some behaviors may thus have a significance for human life that is not best described as adaptive significance.

This argument can be summarized in the terms of Fig. 1A as follows. First, I assume that it is possible to determine empirically the relative fitness benefits derived from various human cultural behaviors. Second, I assume that fitness costs incurred by the reduction (or risk of reduction) of time and energy budgets are probably more difficult to determine, particularly in view of the influence of culture described above. For analytic purposes, it is probably more useful to use an estimate of phenotypic cost (or risk) itself as an indicator of fitness costs. For a closer approximation, phenotypic expenses or risks by individuals of a given age can be multiplied by the average "reproductive value" statistically derived for that age in that population, Fig. 1B (see discussion in Fisher, 1958: 27ff). While this procedure makes no allowance for parental care, weighting costs in this fashion corrects for the uneven age distribution of reproductive opportunity. My prediction is that the estimated phenotypic costs and inclusive fitness benefits for the various behaviors of an individual in a given human society will be correlated with a general pattern as shown in Fig. 1C.

Two features of this association are particularly important to this discussion: (1) the strong though perhaps nonlinear correlation between costs and benefits for medium- to high-cost behaviors and (2) the existence of considerable variance overall but particularly for low-cost activities. The first prediction is the most obvious to test. The second is perhaps just as important. It is a challenge to those who suggest reductionism and a reply to those who criticize an evolutionary approach on grounds that it can explain everything and therefore nothing. The wide variance shown at the low end of the plot acknowledges that these behaviors are relatively inconsequential in terms of fitness and are therefore probably retained for phenotypic rewards. The amount of such variance is expected to increase with the cultural expansion of an individual's phenotype and, in many cases, the behaviors represented at this end of the graph can be better 
explained in terms of other criteria. Additional scatter can result from "incomplete" selection. Because of the continuous introduction of variability in cultural traits at a high rate, any given behavior may not have been subject to selective retention for very long. In general, though, I predict that the more phenotypically costly a behavior is, the more variance fitness alone can explain.

The null hypothesis, which effectively claims that cultural practices are independent of our ability to survive and reproduce, is shown in Fig. 1D. This kind of scatter is predicted by a recent theory (Cloak, 1975) suggesting that culture evolves "like an active parasite" to maximize its own replication "irrespective of its value for the survival/reproduction of the organism which carries it or the organism's conspecifics" (p. 172). By this reasoning, we would expect to find a substantial number of high-cost low-benefit altruistic behaviors perpetuated in a society by cultural processes (a similar conflict between biological and cultural evolution is suggested by Campbell, 1972). While the definitive test of opposing theories must come from data analysis, Cloak's theory is suspect since it ignores the ability of human beings to cure themselves, so to speak, of deleterious "cultural parasitism" by adopting beneficial (or less deleterious) practices as they are introduced. A priori the replication of a cultural trait may thus depend on its value to the host rather than on "its value for the survival/replication of itself or its replicas" (Cloak, 1975: 172).

If the preceding arguments are valid, the importance of inclusive fitness to our understanding of human behavior will be conditionally dependent on the degree to which any behavior taxes the highly variable amount of time and energy available to an individual. Because of our readily expandable phenotypic budgets, low-cost forms of human social behavior may make more sense in terms of profit, wealth, satisfaction, happiness, fame, etc., than they make in terms of even the most sophisticated fitness argument. This suggests that while we may tend to behave in ways that maximize our fitnesses culture enables us to do other important things as well. It would therefore be a serious mistake to suggest or imply that all kinds of human behavior can best be interpreted in terms of inclusive fitness. My proposition is that the adaptive significance of cultural traits can always be traced to their fitness-enhancing benefits for individuals. I do not propose that this is necessarily their total significance. In our analysis of human behaviors, variance not readily attributable to inclusive fitness may have significance in other ways.

In short, I see no reason to believe that culture can be reduced to a purely biological explanation (see also Bates, 1967). While I criticize theories of culture change based on other selection criteria for their inabilities to apply as generally as they propose, and for their failure to be explicitly complementary to organic evolution, I agree with the claim that selective retention in cultural evolution can best be viewed as a multicriterion process and that at least some nonfitness cri- 
teria are important in and of themselves. Simply stated, my hypothesis is that any selective retention by these other criteria does not generally run counter to the inclusive fitnesses of individual human beings.

In many ways, earlier theories of cultural evolution are already consistent with this theory for the selective retention of traits which enhance inclusive fitness. Consider, for example, the documented tendency for the net harvest of energy to increase in the course of cultural evolution. Wherever energy itself, or a resource requiring energy for procurement, constrains the fitnesses of individuals in a population, I would expect selective retention to favor ways of increasing the net availability of energy through either the quantity harvested or the efficiency of use. Further, if it is true that people tend to behave in ways which maximize the propagation of their genes, then it is no surprise that increased population size often accompanies cultural change. Growth can be the cause and/or effect of selective retention consistent with the fitness criterion regardless of whether the limiting resource is energy, food, shelter, or even mates. Similarly, the ability to respond to environmental perturbations and the satisfaction associated with certain behaviors can be related to the notion of inclusive fitness. The understanding of human cultural evolution gained by theories built on these criteria may not contradict the hypotheses presented here. A reformulation in terms of fitness may well be redundant or less interesting and therefore unnecessary. However, a demonstration that cultural selection by any other criterion directly opposes inclusive fitness would be sufficient to refute my arguments.

To conclude this section, let me suggest several ways in which fitness may supplement our present understanding of cultural behavior. First, these arguments can be used to predict limits to the selective retention of customs by other criteria. In contrast to energy theories of cultural evolution, for example, this argument suggests that people are not likely to harvest energy either in a way or in an amount that would cause them reduced fitness. Second, fitness can be used to explain the maintenance of behaviors that appear to be inexplicable or even in opposition to the criteria of other theories of cultural evolution. The satisfaction criterion, for example, is scarcely adequate for explaining cultural patterns of fertility control by abstinence or infanticide. In this case, a smaller number of offspring, or increased spacing between them, may have a net fitness benefit for the parents through their enhanced ability to care for previous children whose survival and reproduction are thus assured (see below). Third, it suggests that we must be suspicious of explanations in any terms proposing that cultural behaviors are dysfunctional for their individual practitioners. Only in this way can the hypotheses presented here be fairly tested.

\section{SUPPORTING EVIDENCE}

Despite the obstacles described above, a number of attempts have been made recently to assess the validity and utility of a "fitness approach" to cultur- 
al adaptation. In these studies, a theory founded on inclusive fitness (and sometimes in terms of natural selection) is used to generate a set of predictions which are then compared with evidence from ethnographic sources. It is important to remember that while the coincidence of observations and theory is striking for the examples below they do not constitute "proof" of the proposed coevolution of organic and cultural adaptations. Not only the products but also the processes of selective retention must be carefully documented before we can accurately assess the validity of the arguments presented here.

\section{Human Aggression}

Surely aggression is one of the most studied of all human behaviors. It is also one of the most hotly debated in terms of instinct and learning. Some biologists and other authors have described the aggressive tendencies of human beings in terms of instincts and imperatives (e.g., Lorenz, 1966; Ardrey, 1966). Anthropologists and others have argued that, above all, aggression is culturally conditioned (see, e.g., Montagu, 1973). In the absence of a satisfying theory for the cultural evolution of aggressive behavior, the debate has lingered because of some consistencies between biological theory and this behavior. Relatively few authors have argued that biology and culture are complementary and that we must therefore consider how both can aid our understanding of human aggression (but see Bigelow, 1972).

Using the notions of inclusive fitness from evolutionary biology and cultural evolution by selective retention from anthropology, I have proposed that the consistencies between biological theory and aggressive behavior are partly explained by the complementary selective retention of cultural attributes (Durham, 1974). The idea is simple: a cultural tradition of collective aggression by the members of a human social group can evolve by selective retention when the cultural phenotype of maximum fitness is aggressive. Given that aggression itself can involve considerable fitness costs (from loss of time and energy or from injury or death), the problem is to show that under special conditions the fitness benefits of aggression more than compensate for its inherent costs. Among other possibilities, this can happen when intergroup aggression results in an increased supply of life-sustaining resources.

To be more specific, consider a hypothetical social group of $G_{1}$ "genotypically selfish" individuals whose selective retention of a particular activity depends on its net effect on the inclusive fitness of those individuals. Assume (1) that the reproductive successes of the members of $G_{1}$ are constrained by the limited availability of a single resource $R$ and (2) that there is low within-group variance in the availability of $R$ so that individuals are affected more or less to the same extent by increases and decreases in resource supply. Under these conditions, any activity by the persons of another social group, $G_{2}$ (or several groups), which reduces the supply of $R$ to $G_{1}$ beyond what it would be in the 
absence of $G_{2}$ automatically decreases the inclusive fitnesses of the individuals in $G_{1}$. Selective retention would then favor aggressive means of reducing this competition as long as (a) the individual costs of collective belligerence are kept below the resulting fitness benefits of resources defended or seized and (b) there is no way for some individuals to reap the benefits without paying the costs of aggression ("freeloading" is not likely to be tolerated by genotypically selfish individuals; see Trivers, 1971). This says very simply that aggressive intergroup behavior can theoretically evolve subject to "genotypically selfish" selective retention. The implication is that this behavioral adaptation need not result from selection operating primarily at levels higher than the individual, as is so often assumed in the anthropological literature on warfare (Otterbein, 1970; Divale, 1973; Harris, 1971, 1974). Beyond that, the model can be used to generate more specific predictions. For example, if we can specify the functional relationship between average per capita consumption of the limited resource and the mean inclusive fitness of the members of a group like $G_{1}$, and if we have information on the relative capabilities of opposing groups for a given set of tactics to serve as an estimate of potential fitness losses, it is possible to predict both the range of resource losses where aggressive behavior is likely and the maximum intensity of aggression (measured in units of fitness cost) that is likely for each value of resource deprivation.

The "test" of the model and its component hypotheses can be attempted by comparing its predictions with independent ethnographic observations. The few test cases I have examined so far (Durham, 1974) appear to support the theory even where the original biases of the observers were to the contrary. For example, I believe this interpretation fits better with the information given by Murphy about Mundurucú headhunting than does his view that external aggression was the safety valve for internal animosities that might have destroyed their social system (Murphy, 1957, 1960). According to the Mundurucú, the trophy heads captured in raids on enemy villages could produce an increase in the abundance of game animals if certain rituals were also observed (including a period of sexual abstinence for the successful warrior). This suggests that the Mundurucu were in competition with other rainforest groups for a limited supply of animal protein. Considering the relative scarcity and mobility of their prey (primarily peccaries and tapir), the elimination of competing consumers may have been the most direct means of increasing or maintaining their own harvest. This interpretation is consistent with Mundurucú food preferences, the central importance of game in their religion, the "mystical" power of the trophy head, and their common reference to enemy groups in the same terms as game, all of which are unaccounted for in Murphy's argument. Although the Mundurucú may not have been conscious of these consequences, the evidence suggests that their headhunting had net benefits for the survival and reproduction of individual parents through the increased supply of animal protein. Ironically, this inference is strengthened by the sanctioned postwar abstinence of trophy takers - in this 
way, the benefits of a raid were distributed widely over the group just as the costs and risks had been. Unfortunately, we know virtually nothing about the evolutionary history of Mundurucú aggression, and this makes it impossible to document the actual operation of selective retention. However, the complex cultural traditions surrounding the headhunt are remarkably consistent with expectations for biologically adaptive cultural behavior.

To this point, both the costs of aggression and the resource benefits are assumed to be distributed with low variance within the belligerent social group. The model becomes more interesting and more useful as this assumption is relaxed. Consider, for example, societies having special positions of authority which exempt privileged individuals from some of the fitness costs of participation in collective enterprise and/or provide them with a disproportionate share of the benefits. Such a social system could be the result of the selective retention process described above if the inclusive fitnesses of other members of the society are (or are believed to be) in some way asymmetrically dependent on the services of the authorities (Durham, 1974). Selective retention as hypothesized would then allow dependents to be manipulated as long as the fitness benefits derived from those with authority are generally greater than the costs of being manipulated. In this way, behavior looking very much like altruism or sacrifice on the part of some individuals could result from the selfish manipulation of authority.

A very dramatic way to generate and use authority is suggested by the research of Chagnon and colleagues on the Yạnomamö of Venezuela (Chagnon, $1968,1974)$. By virtue of their wisdom and/or ferocity, village headmen appear to influence the behavior of their followers in ways that include raids on neighboring villages for women. There is strong evidence that headmen accumulate more wives and then more children and grandchildren than do other men in this way. Chagnon (1974) refers to one headman, Matakuwä, who sired 42 children including a son who then sired 33. The unusual fertility of Matakuwä and his brothers and sons had the result that $45 \%$ of the total population of ten Yąnomamö villages (3311 people) were in some way descendants of his father. There can be little doubt that the manipulation of others by headmen like Matakuwä does have its fitness benefits. Depending on limits prescribed by the fitness dependence of their followers, authorities may be able to influence social behavior to a degree that appears altruistic or group selected on the surface. This adds still another complication to studies of this sort: not everyone need directly benefit from an activity for it to be perpetuated in a society. In fact, months of study may be required to determine just who does benefit.

\section{Reciprocity}

Aggression is not the only form of human cultural behavior that involves considerable phenotypic cost and is therefore expected to show a close association with inclusive fitness. Trivers (1971) proposed, for example, that his 
"model for the natural selection of reciprocally altruistic behavior can readily explain the function of human altruistic behavior and the details of the psychological system underlying such behavior" (p. 48). He argued that reciprocity in the exchange of goods and services could well have an adaptive significance (i.e., net fitness benefits) for individuals and that the notion of group advantage was not necessary even to explain costly acts of altruism which were likely to be reciprocated indirectly or in the long run. While his analysis can be criticized for its explicit assumption that the basis for this behavior is exclusively genetic, it did generate a number of interesting predictions which should still apply if cultural evolution is truly complementary. One of these predictions, that there should be "a lowered demand for reciprocity from kin than from nonkin" (p. 46), is supported in an article by another evolutionary biologist (Alexander, 1975a).

Alexander argues that Sahlins' $(1965,1972)$ observations on the economics of exchange and reciprocity in "primitive" societies are consistent with the theory of evolution by natural selection. Generalized reciprocity appears to be an example of what biologists call kin selection and nepotism, balanced reciprocity is a kind of reciprocal altruism, and negative reciprocity corresponds to a biologist's notion of evolutionary cheating or parasitism. Moreover, the correlation Sahlins describes between these modes of exchange and kinship-residential groupings nicely corresponds to the predictions of Fig. 1 here. Generalized reciprocity, with highest phenotypic cost to individuals, tends to be concentrated in the household and local lineage sectors, as would be expected from the interdependence of relatives' fitnesses. "Reciprocity accordingly inclines toward balance and chicane in proportion to sectoral distance" over village, tribal, and intertribal sectors (Sahlins, 1972: 198); i.e., phenotypic costs decline in proportion to the decreasing average interdependence of inclusive fitnesses. Alexander contends that "Sahlins is telling the evolutionists that their expectations are fulfilled to an astonishing degree in 'primitive' human societies..." While these observations are consistent with expectations for behaviors evolved organically and controlled by genes, there is of course no evidence that natural selection itself was the means by which this social behavior evolved. In the absence of a complementary notion of cultural selection, Alexander's use of "selection for" these behaviors is tainted with biological determinism to a degree that the data do not support and social scientists will flatly deny. For example, his discussion includes an argument that "society is based on lies," many of which permit individuals to seek selfish gains unconsciously. He argues that "selection (meaning natural selection) must have kept some such realizations out of the consciousness of individuals, while simultaneously promoting the kinds of behavior that bring to completion gains such as those described above." Until biologists recognize and include in "selection" the complementary preservation of acquired characteristics, the direct application of natural selection models will remain an effective barrier to a thorough understanding of human social behavior. It is also 
unfortunate that Alexander and other biologists tend to emphasize the selfish, dishonest, and competitive aspects of human existence. Considering that underlying, relentless gene competition is the premise on which all such interpretations are based, the more interesting and awesome feature of our existence is the extent of cooperation and nonnegative reciprocity.

Nonetheless, Sahlins' comments on reciprocity are consistent with the notion that humans tend to behave in ways which maximize their inclusive fitnesses. This applies to several of Sahlins' other analyses of human social systems as well (e.g., Sahlins, 1957, 1961). For example, his recent arguments concerning the economic organization of "stone age" production focus on "each household's devotion to its own interests" and relate "the social inflection of domestic production" to the interdependent welfare of single units in society (Sahlins, 1972). Many of the arguments can be given equivalent experession in terms of inclusive fitness. I am even tempted by his discussion of the "spirit of the gift" to suggest that the Maori had in their use of "hau" a more complete notion of inclusive fitness and its relevance to social affairs than we do (Sahlins, 1972: Chapter 4).

\section{Incest}

In another article, Alexander provides an interpretation of human incest avoidance consistent with current biological theory (Alexander, 1975b). While the discussion is marred by the usual emphasis on natural selection together with the assumption of genetic programming for traits like cooperation and awareness, he gives a reasonable argument that the adaptive significance of incest avoidance lies in the inclusive fitness benefits derived from outbreeding. He suggests that incest taboos evolved in response to the deleterious genetic effects of inbreeding and that they later acquired the additional function of cementing political alliances between groups. In support of this hypothesis, he presents data on the asymmetrical preference for cross and parallel cousin marriages shown by a sample of societies in Murdock's Atlas. In 79 sororally polygynous societies, for example, where parallel cousins would tend to be more closely related than cross-cousins and thus more likely to suffer reduced fitness from the effects of inbreeding, 75 (95\%) favor cross-cousin marriages.

The evidence suggests that minimization of inbreeding is one among several possible adaptive functions (alliances, trade relations, access to resources and labor) of outmarriage. To an important extent, marriage and kinship systems too may be the product of the selective retention of practices which enhance the propagation of individuals' genes. It is a safe bet that inclusive fitness will prove useful to anthropologists who study the complexities of kinship.

Alexander's study raises another important point. He suggests that data on marriages in kibbutzim and on Taiwan "are what one would expect if selection had favored the development of incest aversion." In his view, these data, together with evidence from nonhuman primates, "support" the argument that 
incest avoidance has a genetic basis in humans. "The facts that incest avoidance is essentially universal, evidently ancient, and appears sometimes even when conscious attempts are made to suppress it ..." are necessary evidence to argue for a genetic basis, true enough. But they are by no means sufficient for it. Alexander's interpretation requires, among other things, the unproved assumptions that incest avoidance in nonhuman primates is genetically based and that conditions exist where cultural evolution is insufficient to explain incest avoidance. To me, the data suggest only the futility of trying to dissect coevolutionary factors in order to debate their relative importance. Biologists have an obstinate tendency, perhaps adaptive in their environment, to make everything genetic and hence the result of natural selection. Could that be genetic, too?

\section{Parental Investment and Infanticide}

Behavior that appears to be altruistic can also evolve by "genotypically selfish" selective retention through dependence and manipulation as described above. Trivers (1972, 1974), Ghiselin (1974), and Alexander (1974) discuss a special case of this related to the investment of human parents in their offspring. The argument is based on the older observation that organic evolution can favor increasing parental care of offspring as long as the fitness benefits from the enhanced survivorship (and ultimately fecundity) of the offspring lead to greater genetic representation than would a larger number of offspring receiving less care. When an allowance is made for cultural evolution, this has several possible consequences for human parents and human societies. First, it means that optimum fecundity by the inclusive fitness criterion may be less than maximum fecundity by an amount which depends on the ability of parents to care for their offspring, which may, in turn, depend on conditions in their social and physical environment. Alexander (1974) argues that this explains human infanticide related to twinning, closely spaced babies, and babies arriving during harsh times. This also suggests that we need not rely on a group advantage argument to explain practices like these behind the "natural" regulation of population size in certain human societies (reviewed in Sell, 1974). There is further evidence that postpartum sex taboos and abstinence may serve a related, child-spacing function. As Alexander points out, these cultural practices appear to complement the inherent biological tendency of lactation to inhibit ovulation. In short, a coevolutionary perspective suggests that the fecundity tendencies of parents will depend to a large degree on the ability of parents to ensure the survival and reproduction of their children through parental care. This prediction, consistent with data from various sources (Durham, 1975), is of major consequence to ongoing programs of human birth control and artificial fecundity regulation the world over.

Second, it means that parental manipulation may influence the sex as well as the number of offspring. Again because of physical and social conditions and the ability of parents to "invest," offspring of one sex may be likely to contribute more than offspring of the other sex to the fitness of parents. The sex- 
preferential infanticide reported for many human societies may thus be the product of selective retention. For example, the preference of parents in polygynous societies for male first-born and the "natural" statistical bias for male babies born to very young mothers may be yet another example of the complementarity of organic and cultural evolution (see Alexander, 1974).

Related arguments by these authors may also help explain parent-offspring conflict, the rearing of nonreproductive (e.g., celibate) children, and even polyandry among human beings. It is consistent with the predictions of Fig. 1 that the most striking associations of cultural behavior and fitness advantages described to date are for relatively high-cost practices. Still, it bears reemphasis that even strong and ubiquitous agreement between models based on natural selection and observed cultural behavior is not proof of their organic evolution. Since it can be argued as above that cultural means of adaptation are the more powerful (e.g., Simpson, 1972), a cultural explanation may even be more plausible for these cases. The point, however, is not to prolong by arguments in either direction the debate of instinct vs. learning. It is rather to realize that cultural and biological traits may be adaptive in the same sense and that it may no longer be possible to treat them as independent (see also Katz et al., 1974).

Many studies of cultural adaptation in the literature are already implicitly consistent with the major hypotheses of this article (some examples may be found in Vayda, 1969; Cohen, 1974b; Harris, 1974). Others require a reinterpretation of group-level phenomena and their relation to the reproductive interests of individuals. Even where intersocietal selection has been assumed to be the primary modus operandi of cultural evolution, a reexamination of the evidence may suggest that cultural behavior has adaptive significance for individual human beings. The arguments here do not deny or discredit the evidence for intersocietal selection. Indeed, many authors propose that the acceleration of changes made possible by group-level extinction and replacement may be the key to understanding our rapid biological and cultural evolution (Keller, 1915; Davie, 1929; Keith, 1949; Reynolds, 1966; Alexander and Tinkle, 1968; Bigelow, 1969, 1972; Carneiro, 1970a,b; Wilson, 1973a; Alexander, 1974). Rather, these arguments suggest that intersocietal selection has rarely if ever resulted in the evolution of a cultural practice (or indeed a complete social system) where individuals customarily and voluntarily behave in ways that constitute genotypic altruism. They suggest that we will find very few cultural practices that are maintained in the absence of force or threat and persist even though individual parents would achieve substantially higher fitness without them or by available alternative practices.

\section{SUMMARY AND CONCLUSION}

While we have known for years that the organic and the cultural evolution of human beings are interdependent, mutually complementary processes, re- 
searchers in biology and anthropology have not yet taken full advantage of the implication that many of our biological and cultural traits can therefore be analyzed in similar terms. Several biologists have suggested that cultural practices may be interpreted in terms of natural selection and genetic evolution. While there are striking consistencies between neo-Darwinian biological theory and human cultural behavior, I do not believe that this means that our behaviors are controlled by genes whose frequencies were increased by natural selection. Rather, I have proposed that this correlation may largely result from a complementary process of cultural selection which influences the retention of cultural traits according to the same criterion as natural selection (i.e., inclusive fitness) by operating generally at the same level (interindividual). There is now some evidence to suggest that in any given environment humans do tend to behave in ways that maximize the long-term representation of their genes in a population. This evidence, of course, by no means constitutes proof for a theory of cultural evolution by the selective retention of traits enhancing the inclusive fitnesses of individuals. Not only does the general applicability of this approach remain to be tested, but also we need more information about the mechanisms of variation, selection, and retention of culturally transmitted traits. However, the evidence

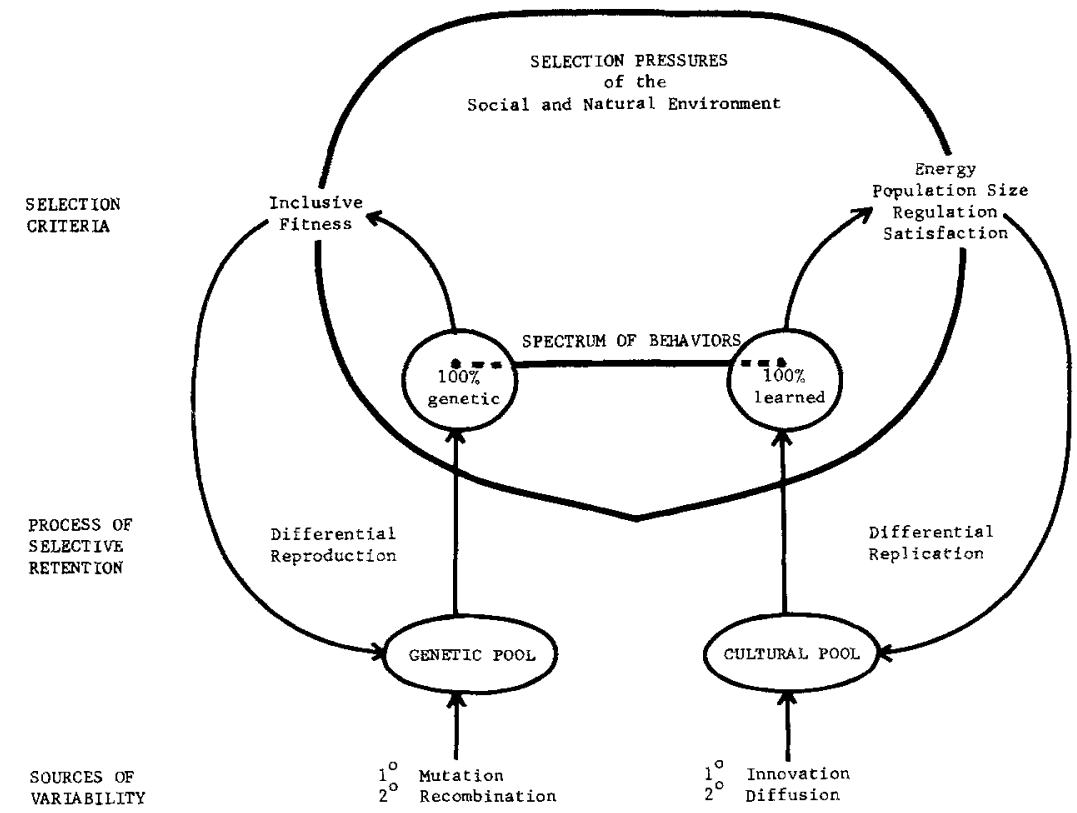

Fig. 2. The evolution of adaptive behaviors by "separationist" theories (adapted with modifications from Ruyle, 1973). Despite analogies between the processes of organic and cultural evolution, earlier theories predicted the selective retention of human behaviors according to different criteria. Considerable insight has been gained by analyses of cultural attributes in terms of energy, population size, regulation, or satisfaction, but not one of these criteria can both stand for the general case and explain the complementary, interdependent relationship of organic and cultural evolution. 


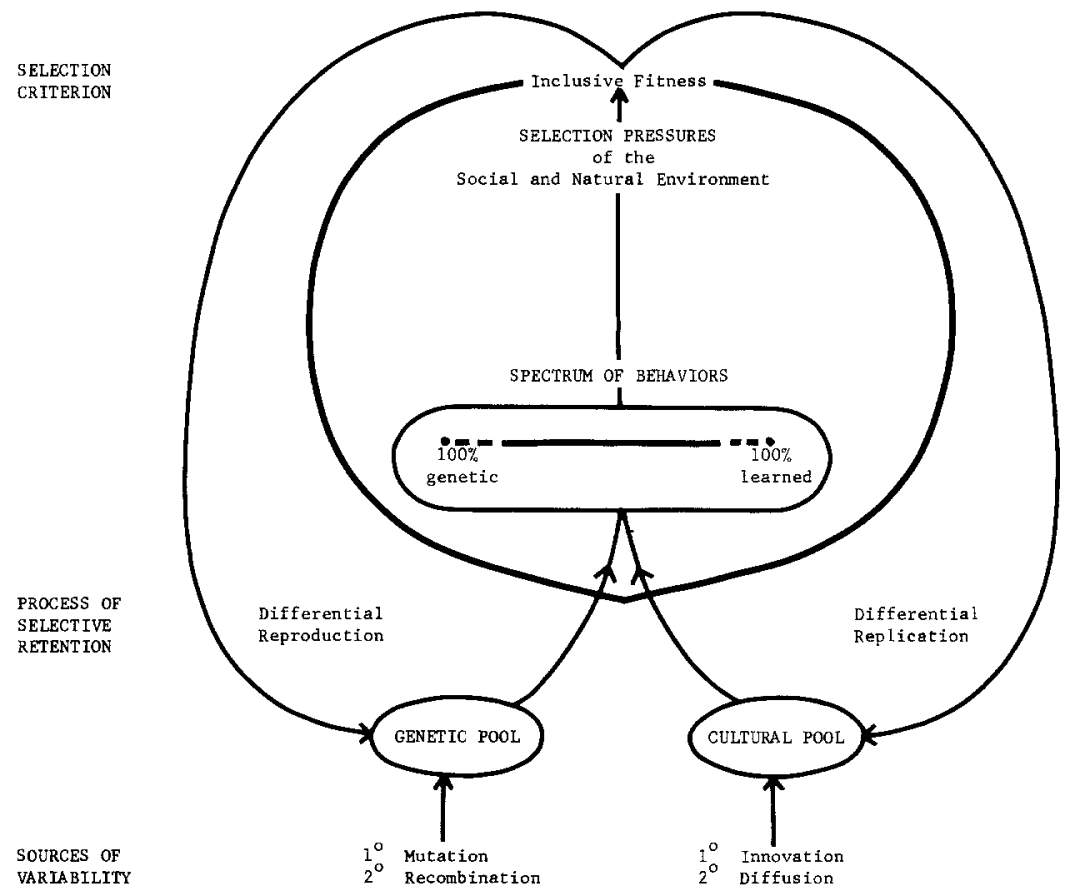

Fig. 3. The "coevolution" of adaptive behaviors. Biological and cultural evolution are pictured as separate but complementary processes owing to a common criterion of selective retention. For schematic simplicity, the developmental interaction of genes and culture is not shown. Unlike separationist theories, this scheme readily explains the interdependent, mutually complementary nature of organic and cultural evolution. If valid, coevolution has a number of broad implications for the study of human ecology and behavior.

does suggest that inclusive fitness may prove to be a useful, analytic tool for understanding human cultural behavior.

I have discussed a number of problems associated with this approach. Some are really only misunderstandings of what inclusive fitness is and what coevolution implies. More serious criticisms stem from inherent problems of measurement and from the complexity of analysis required by a focus on individuals in society. Still others result from the overzealous application of a theory that predicts only a correlation between the measurable phenotypic costs of different behaviors and their fitness-enhancing benefits to individuals. Again, these arguments do not suggest that inclusive fitness is the best or only measure for explaining every human activity. Particularly for low-cost activities, there may be considerable additional variance better explained, for example, by phenotypic rewards. Realistically, we must acknowledge that humans strive for a whole variety of things supplemental to fitness, such as profit, wealth, power, happiness, selfsatisfaction, and fame. We must therefore avoid the implication that the adaptive significance is the total significance of human activities. 
Perhaps the most important implication of this approach to the study of humans is that it may be possible to formulate a general theory for the coevolution of human biology and culture. In the study of human behavior is perhaps the best example of a growing antagonism between the biological and social sciences concerning the relative importance of biology and socialization to human attributes. If the theory described here can successfully resolve some of the polemic differences that have arisen in this particular area, similar arguments may be applicable to other subfields in the study of human beings.

Figures 2 and 3 summarize the similarities and differences between the "separationist" theories of human behavior and the "coevolutionary" theory described here. Both figures are based on the assumption that all forms of human behavior could in theory be located along a spectrum running from $100 \%$ genetically programmed to $100 \%$ learned. In the past (Fig. 2), there has been a tendency for anthropologists and biologists to deny, discredit, or ignore one end of the spectrum or the other in favor of traditional disciplinary biases of interpretation. Even those who accept the relevance of both inputs have insisted on some separation or discontinuity between them. A recent "unified" theory (Ruyle, 1973), for example, allows for appropriate similarities and differences in the processes of organic and cultural evolution but insists that genetic and cultural attributes are selected separately and according to different criteria. The general standard suggested for the selective retention of cultural traits (satisfaction) could easily result in noncomplementary, nonadaptive hedonism.

In contrast, $I$ have argued that the complementarity of organic and cultural evolution (which is, incidentally, acknowledged by many of those who insist on debating instinct and learning) implies that there is also a common criterion behind the selection processes that remain separable in principle (Fig. 3). It is my feeling that a unified theory of biological and cultural evolution is more readily achieved through emphasis on the criteria of selection than on analogies between the processes. This perspective has the additional advantage of explaining both how culture and biology come to be adaptive in the same sense and how they may interact in the evolution of human attributes ( $c f$. Mettler, 1962; Weisenfeld, 1967; McCracken, 1971; Katz et al., 1974). In contrast to earlier explanations, this suggests that distinctions between genetic and learned influences may not be especially relevant to understanding why people do what they do.

\section{ACKNOWLEDGMENTS}

I thank Alexander Alland, Jr., Fred Bookstein, Doug Boucher, Kathy Durham, Brian Hazlett, Dan Janzen, Dick Levins, Olga Linares, Roy Rappaport, Steve Risch, Vicki Sork, John Vandermeer, and Andrew P. Vayda for comments and criticism. I also thank Colin Pittendrigh, who first suggested to me years ago 
that the complete instructions on "how to do it" are not confined to nucleotide sequences in DNA.

\section{REFERENCES}

Alcock, J. (1975). Animal Behavior: An Evolutionary Approach. Sinauer Associates, Sunderland, Mass.

Alexander, R. D. (1971). The search for an evolutionary philosophy of man. Proceedings of the Royal Society of Victoria 84(1): 99-120.

Alexander, R. D. (1974). The evolution of social behavior. Annual Review of Ecology and Systematics 5: 325-383.

Alexander, R. D. (1975a). The search for a general theory of behavior. Behavioral Science 20(2): 77-100.

Alexander, R. D. (1975b). Incest, culture, and natural selection. In Dobzhansky, T., Hecht, M. K., and Steere, W.C. (eds.), Evolutionary Biology, Vol. 8, Plenum Press, New York.

Alexander. R. D., and Tinkle, D. W. (1968). (A comparative book review of On Aggression by K. Lorenz and The Territorial Imperative by R. Ardrey.) Bioscience 18: 245-248.

Alland, A. (1969). Ecology and adaptation to parasitic diseases. In Vayda, A. P. (ed.), Environment and Cultural Behavior, Natural History Press, Garden City, N.Y., pp. 80-89.

Alland, A. (1970). Adaptation in Cultural Evolution: An Approach to Medical Anthropology, Columbia University Press, New York.

Alland, A. (1972). The Human Imperative, Columbia University Press, New York, 177 pp.

Alland, A. (1973). Evolution and Human Behavior, 2nd ed., Anchor Press, Garden City, N.Y.

Alland, A. (1975). Adaptation. Annual Review of Anthropology 4: 59-73.

Alland, A., and McCay, B. (1973). The concept of adaptation in biological and cultural evolution. In Honigmann, J. J. (ed.), Handbook of Social and Cultural Anthropology, Rand McNally, Chicago, pp. 143-178.

Ardrey, R. (1966). The Territorial Imperative, Atheneum, New York.

Bajema, C. J. (ed.) (1971). Natural Selection in Human Populations, Wiley, New York.

Barkow, J. H. (1973). Darwinian psychological anthropology: A biosocial approach. Current Anthropology 14(4): 373-387.

Barnett, H. G. (1953). Innovation: The Basis of Cultural Change, McGraw-Hill, New York.

Bates, M. (1967). Gluttons and Libertines, Vintage, New York.

Bigelow, R. (1969). The Dawn Warriors: Man's Evolution Towards Peace, Little, Brown, Boston.

Bigelow, R. (1972). The evolution of cooperation, aggression, and self-control. Nebraska Symposium on Motivation 20: 1-57.

Campbell, D. T. (1965). Variation and selective retention in sociocultural evolution. In Barringer, H. R., Blanksten, G. I, and Mach, R. W. (eds.), Social Change in Developing Areas: A Re-interpretation of Evolutionary Theory, Schenkman, Cambridge, Mass., pp. 19-48.

Campbell, D. T. (1972). On the genetics of altruism and the counter-hedonic components in human culture. Journal of Social Issues 28(3): 21-37.

Carneiro, R. L. (1970a). A theory of the origin of the state. Science 1969: 733-738.

Carneiro, R. L. (1970b). Foreword to K. F. Otterbein, The Evolution of War: A CrossCultural Study, HRAF Press, New Haven.

Caspari, E. (1963). Selective forces in the evolution of man. American Naturalist 97: 5-14.

Cavalli-Sforza, L., and Feldman, M. W. (1973). Models for cultural inheritance. I. Group mean and within group variation. Journal of Theoretical Population Biology 4: 42-55.

Chagnon, N. A. (1968). Yanomamö: The Fierce People, Holt, Rinehart and Winston, New York, $142 \mathrm{pp}$.

Chagnon, N. A. (1974). Studying the Yanomamö, Holt, Rinehart and Winston, New York.

Cloak, F. T. (1975). Is a cultural ethology possible? Human Ecology 3(3): 161-182. 
Cohen, Y. A. (1974a). Culture as adaptation. In Cohen, Y. A. (ed.), Man in Adaptation: The Cultural Present, 2nd ed., Aldine, Chicago, pp. 45-68.

Cohen, Y. A. (1974b). Man in Adaptation: The Cultural Present, 2nd ed., Aldine, Chicago. Cook, E. (1971). The flow of energy in an industrial society. Scientific American 224: 134.

Corning, P. A. (1974). Politics and the evolutionary process. In Dobzhansky, T., Hecht, M. K., and Steere, W. C. (eds.), Evolutionary Biology, Vol. 7, Plenum Press, New York, pp. 253-294.

Darlington, C. D. (1969). The Evolution of Man and Society, Simon and Schuster, New York.

Darlington, P. J. (1972). Nonmathematical models for evolution of altruism, and for group selection. Proceedings of the National Academy of Science 69(2): 293-297.

Davie, M. R. (1929). The Evolution of War: A Study of Its Role in Early Societies, Yale University Press, New Haven.

Divale, W. T. (1973). Warfare in Primitive Societies: A Bibliography, ABC-CLIO Press, Santa Barbara, Calif.

Dobzhansky, T. (1961). Man and natural selection. American Scientist 49: 285-299.

Dobzhansky, T. (1962). Mankind Evolving: The Evolution of the Human Species, Yale University Press, New Haven.

Dobzhansky, T. (1963). Cultural direction of human evolution. Human Biology 35: 311-316.

Dobzhansky, T. (1972). Unique aspects of man's evolution. In Pringle, J. W. S. (ed.), Biology and the Human Sciences, Clarendon Press, Oxford, pp. 121-139.

Dobzhansky, T., and Montagu, M. F. A. (1947). Natural selection and the mental capacities of mankind. Science 105: 587-590.

Durham, W. H. (1974). Resource competition and human aggression. Part I: A review of primitive war. Paper presented at the Smithsonian Conference on Human Biogeography, April 1974 (to be published).

Durham, W. H. (1975). The coevolution of human biology and culture. Ms.

Emlen, J. M. (1966). Natural selection and human behavior. Journal of Theoretical Biology 12: $410-418$.

Fisher, R. A. (1958). The Genetical Theory of Natural Selection, 2nd ed., Dover, New York.

Flannery, K. V. (1972). The cultural evolution of civilizations. Annual Review of Ecology and Systematics 3: 399-426.

Freedman, D. G. (1967). A biological view of man's social behavior. In Etkin, W. (ed.), Social Behavior from Fish to Man, University of Chicago Press, Chicago, pp. 152-188.

Freedman, D. G. (1968). An evolutionary framework for behavioral research. In Vandenberg, S. G. (ed.), Progress in Human Behavior Genetics, Johns Hopkins Press, Baltimore.

Ghiselin, M. T. (1974). The Economy of Nature and the Evolution of Sex, University of California Press, Berkeley.

Goldschmidt, W. (1972). An ethnography of encounters: A methodology for the enquiry into the relation between the individual and society. Current Anthropology 13(1): 59-78.

Hamilton, W. D. (1963). The evolution of altruistic behavior. American Naturalist 97(896): 354-356.

Hamilton, W. D. (1964). The genetical evolution of social behavior. Parts I and II. Journal of Theoretical Biology 7: 1-52.

Hamilton, W. D. (1970). Selfish and spiteful behavior in an evolutionary model. Nature 228(5277): 1218-1220.

Hamilton, W. D. (1971). Selection of selfish and altruistic behavior in some extreme models. In Eisenberg, J. F., and Dillon, W. S. (eds.), Man and Beast: Comparative Social Behavior, Smithsonian Press, Washington, D.C., pp. 59-91.

Hamilton, W. D. (1972). Altruism and related phenomena, mainly in the social insects. $A n$ nual Review of Ecology and Systematics 3: 193-232.

Hardin, G. (1959). Nature and Man's Fate, Rinehart, New York.

Harner, M. J. (1973). Hallucinogens and Shamanism, Oxford Press, New York.

Harris, M. (1971). Culture, Man and Nature, Crowell, New York. 
Harris, M. (1974). Cows, Pigs, Wars, and Witches: The Riddles of Culture, Ramdom House, New York.

Johnson, A. W. (1972). Individuality and experimentation in traditional agriculture. Human Ecology 1(2): 149-159.

Kaplan, D., and Manners, R. A. (1972). Culture Theory, Prentice-Hall, Englewood Cliffs, N.J.

Katz, S. H., Hediger, M. L., and Valleroy, L. A. (1974). Traditional maize processing techniques in the New World. Science 184: 765-773.

Keith, A. (1949). A New Theory of Human Evolution, Watts, London.

Keller, A. G. (1915). Societal Evolution, Macmillan, New York.

Kummer, H. (1971). Primate Societies: Group Techniques of Ecological Adaptation, Aldine, Chicago.

Lewontin, R. C. (1970). The units of selection. Annual Review of Ecology and Systernatics 1: $1-18$.

Lewontin, R. C. (1974). The Genetic Basis of Evolutionary Change, Columbia University Press, New York.

Lorenz, K. (1966). On Aggression, Harcourt, Brace and World, New York.

McBride, G. (1971). The nature-nurture problem in social evolution. In Eisenberg, J. F., and Dillon, W. S. (eds.), Man and Beast: Comparative Social Behavior, Smithsonian Press, Washington, D.C., pp. 37-56.

McCracken, R.D. (1971). Lactase deficiency: An example of dietary evolution. Current Anthropology 12(4,5): 479-517.

Meggers, B. J. (1971). Amazonia: Man and Culture in a Counterfeit Paradise, Aldine, Chicago.

Meggers, B. J. (1973). Some problems of cultural adaptation in Amazonia, with emphasis on the Pre-European period. In Meggers, B. J., et al. (eds.), Tropical Forest Ecosystems in Africa and South America, Smithsonian, Washington, D.C., pp. 311-320.

Mettler, F. A. (1962). Culture and the structural evolution of the nervous system. In Montagu, M. F. A. (ed.), Culture and the Evolution of Man, Oxford University Press, New York, pp. 155-201.

Montagu, M. F. A. (ed.) (1962). Culture and the Evolution of Man, Oxford University Press, New York.

Montagu, M. F. A. (ed.) (1968a). Culture: Man's Adaptive Dimension, Oxford University Press, New York.

Montagu, M. F. A. (1968b). Brains, genes, culture, immaturity, and gestation. In Montagu, M. F. A. (ed.), Culture: Man's Adaptive Dimension, Oxford University Press, New York, pp. 102-113.

Montagu, M. F. A. (ed.) (1973). Man and Aggression, 2nd ed., Oxford University Press, New York.

Murdock, G. P. (1956) (rev. 1971). How culture changes. In Shapiro, H. C. (ed.), Man, Culture, and Society, Oxford University Press, New York, pp. 319-332.

Murphy, R. F. (1957). Intergroup hostility and social cohesion. American Anthropologist 59: 1018-1035.

Murphy, R. F. (1960). Headhunter's Heritage, University of California Press, Berkeley.

Otterbein, K. F. (1970). The Evolution of War, HRAF Press, New Haven.

Rappaport, R. A. (1969). Sanctity and Adaptation, Wenner-Gren Foundation, New York.

Rappaport, R. A. (1971a). The sacred in human evolution. Annual Review of Ecology and Systematics 2: 23-44.

Rappaport, R. A. (1971b). Nature, culture, and ecological anthropology. In Shapiro, H. (ed.), Man, Culture and Society, Oxford University Press, New York, pp. 237-267.

Reynolds, V. (1966). Open groups in hominid evolution. Man 1(4): 441-452.

Roe, A., and Simpson, G. C. (eds.) (1958). Behavior and Evolution, Yale University Press, New Haven.

Ruyle, E. E. (1973). Genetic and cultural pools; Some suggestions for a unified theory of biocultural evolution. Human Ecology 1(3): 201-215.

Sahlins, M. D. (1957). Land use and the extended family in Moala, Fiji. American Anthropologist 59: 449-462. 
Sahlins, M. D. (1961). The segmentary lineage: An organization of predatory expansion. American Anthropologist 63: 322-343.

Sahlins, M. D. (1965). On the sociology of primitive exchange. In Banton, M. (ed.), The Relevance of Models for Social Anthropology, Association of Social Anthropologists Monograph 1, London, pp. 139-236.

Sahlins, M. D. (1972). Stone Age Economics, Aldine, Chicago.

Sanders, W. T., and Price, B. (1968). MesoAmerica: The Evolution of a Civilization, Random House, New York.

Sell, D. W. (1974). Population regulation in "primitive" societies: An evolutionary approach to human behavior. Honors thesis, University of Michigan.

Simpson, G. G. (1961). Comments of cultural evolution. Daedalus 90: 514-518.

Simpson, G. G. (1964). This View of Life, Harcourt, Brace and World, New York.

Simpson, G. G. (1966). The biological nature of man. Science 152: 472-478.

Simpson, G. G. (1972). The evolutionary concept of man. In Campbell, B. (ed.), Sexual Selection and the Descent of Man, Aldine, Chicago, pp. 17-39.

Spuhler, J. M. (ed.) (1959). The Evolution of Man's Capacity for Culture, Wayne State University Press, Detroit.

Stern, J. J. (1970). The meaning of adaptation and its relation to the phenomenon of natural selection. In Dobzhansky, T., Hecht, M. K., and Steere, W. C. (eds.), Evolutionary Biology, Vol. 4, Appleton-Century-Crofts, New York, pp. 39-66.

Steward, J. (1955). Theory of Culture Change, University of Illinois Press, Urbana.

Stott, D. H. (1962). Cultural and natural checks on population growth. In Montagu, M. F. A. (ed.), Culture and the Evolution of Man, Oxford University Press, New York, pp. 355-376.

Tiger, L., and Fox, J. R. (1966). The zoological perspective in social science. Man 1(1): $75-81$.

Tiger, L., and Fox, J. R. (1971). The Imperial Animal, Dell, New York.

Trivers, R. L. (1971). The evolution of reciprocal altruism. Quarterly Review of Biology 46: 35-37.

Trivers, R. L. (1972). Parental investment and sexual selection. In Campbell, B. (ed.), Sexual Selection and the Descent of Man, Aldine, Chicago, pp. 136-179.

Trivers, R. L. (1974). Parent-offspring conflict. American Zoologist 14: 249-264.

Trivers, R. L., and Willard, D. E. (1973). Natural selection of parental ability to vary the sex ratio of of fspring. Science 179: 90-92.

Turnbull, C. (1972). The Mountain People, Simon and Schuster, New York.

Vayda, A. P. (1961). Expansion and warfare among swidden agriculturalists. American Anthropologist 63: 346-358.

Vayda, A. P. (ed.) (1969). Environment and Cultural Behavior, Natural History Press, Garden City, N.Y.

Waddington, C. H. (1960). The Ethical Animal, University of Chicago Press, Chicago.

Weisenfeld, S. L. (1967). Sickle cell trait in human biological and cultural evolution. Science 157: $1134-40$.

West Eberhard, M. J. (1975). The evolution of social behavior by kin selection. Quarterly Review of Biology 50(1): 1-33.

White, L. A. (1949). The Science of Culture, Farrar, Straus and Cudahy, New York.

White, L. A. (1959). The Evolution of Culture, McGraw-Hill, New York.

Whiting, J. (1964). Effects of climate on certain cultural practices. In Goodenough, W. (ed.), Explorations in Cultural Anthropology, McGraw-Hill, New York.

Wilbur, H. M., Tinkle, D. W., and Collins, J. P. (1974). Environment certainty, trophic level, and resource availability in life history evolution. American Naturalist 108(964): 805-817.

Williams, G. C. (1966). Adaptation and Natural Selection, Princeton University Press, Princeton, N.J.

Williams, G. C. (ed.) (1971). Group Selection, Aldine-Atherton, Chicago.

Wilson, E. O. (1971). The Insect Societies, Harvard University Press, Cambridge, Mass. 
Wilson, E. O. (1973a). The queerness of social evolution. Bulletin of the Entomological Society of America 19: 20-22.

Wilson, E. O. (1973b). Group selection and its significance for ecology. Bioscience 23: 631-638.

Wilson, E. O. (1975). Sociobiology: The New Synthesis, Harvard (Belknap), Cambridge, Mass.

Wynne-Edwards, V. C. (1962). Animal Dispersion in Relation to Social Behavior, Hafner, New York.

Wynne-Edwards, V. C. (1963). Intergroup selection in the evolution of social systems. Nature 200: 623-626. 